\title{
Imbalance in Prehypertension Effect on the Myocardial Works for the Student of Medical College \\ Ibrahim T Ibrahim (MSc) ${ }^{1}$ \\ Abstract
}

Background: Imbalance in prehypertension represent one of the mean causes that effect in the myocardial work loud and causes stress on heart in different position for both gender in different ages healthy or non-healthy this study healthy young male and female student in the college of medicine as a volunteers.

Objective: To study the effect of stress during the lecture on the heart for female and male in both position sitting and standing.

Patients and Methods: 20 healthy looking medical students of age between 23-24 years old of both genders were participated in the study they are divided in two group male and female with standing and sitting position.

Results Correlation between the heart rate in sitting position and heart rate in the standing position as it is seen there are an increasing in both sitting and standing, $\mathrm{R} 2=(0.3356)$ significant in standing $. \mathrm{R} 2=(0.1149)$ also significant in the sitting.

Conclusion: Find from this study that female total value increase on the sitting and standing position where male decrease in both positions.

Keywords: Cardiovascular, Rate-pressure product, Systolic and Diastolic blood pressure.

Corresponding Author: Ibr-33@gmail.com

Received: $22^{\text {th }}$ January 2019

Accepted: $31^{\text {th }}$ January 2019

\footnotetext{
${ }^{1}$ College of Medicine - University of Diyala - Diyala - Iraq.
}

\section{Introduction}

Blood pressure in young healthy adults is effect on the myocardial and cusses stress, and this refer to some think abnormal if there is no any problem seen, so the prehypertension associated with adverse cardiovascular (CV) events [1].Healthy lifestyle and exercise can often control prehypertension if the person continue on it every day without any disability. The increase psychosocial stress has participated to the increase of hypertension and prehypertension, in addition to the contribution of physical in activity [2]. Sympathovagal imbalance in prehypertension relevance with myocardial works stress in healthy female or male both of the together or alone [3]. There are synthesis interactions amongst the sympathetic and parasympathetic nervous system inputs to the sinus nods, so mixing emotion has a relationship in raising blood pressure and stress on the heart muscle [4]. Blood pressure 
is one of the ways to measure changes within the human body easily without any negative impact and has an indicator health in general. Measurements of the blood pressure can be influence by body position in healthy young student, Gravitation has the main effect in the measurements of the blood pressure if the body sitting or standing and this through the effect of supplying the body with blood and also relax the muscles or the spread of the student as well as pressure on the internal intestines [5]. So in the present study the relationship between the rate-pressure products (RPP) and imbalance prehypertension has appeared between the two groups the female and the male. Cardiovascular risk factors associated with position that involve combinations of sitting, standing in the classroom, and walking for differed health female and male, with these position associated with lower cardiovascular risk estimates among male but elevated risk estimates among female. student in class room with sitting and standing position may be effected by some stress during the lecture many causes effect on them one of this is ventilation the lack of fresh air or increase in exhalation air outside the mouth of students and temperature, if its high it affects the rate of blood flow in the body more than the normal limit, and sound as well as sound in the classroom the loudness or lowness of the sound has a direct effect through the emotions and movement of the student annoyance, which is one of the problems in our classroom [6].

\section{Patients and Methods}

After obtaining the approval of research department in Diyala medical college and case study permissions, participants were explained about their participation and the nature of investigations to be carried out in the project. The data was obtained from all of participant prior to the recordings. The agematched normotensives served as controls. Prehypertensive and normotensives were grouped based on their level of systolic and diastolic blood pressure (SBP and DBP).

Subjects to antihypertensive therapy or receiving any medication, with history of smoking and/or alcoholism, with acute or chronic ailments, performing regular sports activities, and known cases of diabetes mellitus, hypertension, cardiac diseases, kidney disease or any endocrinal disorder were excluded from this study.

20 healthy looking medical students of age between 23-24 years old of both genders were participated in the study .The instrument used to measurement for blood pressure is electronic barometer. The students had been checked for blood pressure and pulse rate before the session and the lecture in both sitting and standing position, the same was done after the session and the lecture.

\section{Statistical analysis}

Excel version 2010 were used for statistical analysis. All the data were expressed as mean \pm standard deviation, $\mathrm{P}$ value $<0.05$ was considered statistically significant. 


\section{Results}

The data presented in this section divided to two groups. Each group has (14) female, (7) male with healthy or normal case. The first table show that data was taken before secession and after secession are significant where $(91.1,97.2)$ and SD $(11.9,10.6)$ for heart rate and systolic in $(\mathrm{mmHg})$ where $(114,118)$ and there are a little change in diastolic $(8.7,8.4)$ with a total pulse pressure (32.9, 36.9) and the mean arterial BP the change ,myocardial workload ( 105.3, 115.5) . The second group of male listed in table shows that little change in SD heart rate but in systolic $(\mathrm{mmHg})$ there is decrease before secession (139.3, 134.7) and increase in diastolic $(90.1,94)$ and the pulse pressure (mmHg) (49.1, 40.7). a little change in mean arterial $\mathrm{BP}(\mathrm{mmHg})$, in total there are an increasing in female by $(9.7 \%)$ and increasing in male by $(4 \%)$ in all variables between group of female and male.

The second table the result shows also increase in the first group of female before and after secession where $(96.6,103.0)$ but systolic decrease and diastolic increase (79.0, $82.6)$ the pulse pressure in $(\mathrm{mmHg})$ before where (40.4) and after (32.8), mean arterial $\mathrm{BP}$ it is show increase.

The result expressed as mean $\mathrm{SD}$ is compare with corresponding value where $(3.3 \%)$ increase and after secession decrease $(2.5 \%)$.

Figure(1) represent the correlation between the heart rate in sitting position and heart rate in the standing position as it is seen there are an increasing in both sitting and standing, $\mathrm{R} 2=(0.3356)$ significant in standing . R2=( 0.1149 ) also significant in the sitting.

Table (1): Effects of laboratory stress on the hemodynamic parameter at sitting position.

\begin{tabular}{|c|c|c|c|c|}
\hline \multirow[t]{2}{*}{ Variables } & \multicolumn{2}{|c|}{ Female $(\mathrm{n}=14)$} & \multicolumn{2}{|c|}{ Male $(n=7)$} \\
\hline & $\begin{array}{l}\text { Before } \\
\text { session }\end{array}$ & After session & $\begin{array}{l}\text { Before } \\
\text { session }\end{array}$ & After session \\
\hline Heart Rate (bpm) & $91.1 \pm 11.9$ & $97.2 \pm 10.6$ & $100.1 \pm 9.4$ & $99.3 \pm 10.0$ \\
\hline Systolic BP (mmHg) & $114.6 \pm 13.1$ & $118.2 \pm 12.0$ & $139.3 \pm 10.3$ & $134.7 \pm 9.5$ \\
\hline Diastolic BP (mmHg) & $81.7 \pm 7.0$ & $81.4 \pm 9.7$ & $90.1 \pm 6.7$ & $94.0 \pm 4.9$ \\
\hline Pulse pressure (mmHg) & $32.9 \pm 10.7$ & $36.9 \pm 11.1$ & $49.1 \pm 9.6$ & $40.7 \pm 10.8 *$ \\
\hline Mean arterial $\mathrm{BP}(\mathrm{mmHg})$ & $92.7 \pm 8.1$ & $92.3 \pm 25.9$ & $106.5 \pm 6.7$ & $107.6 \pm 4.5$ \\
\hline Myocardium workload & $105.3 \pm 22.2$ & $115.5 \pm 21.6(9.7 \% \uparrow)$ & $139.2 \pm 14.5$ & $133.6 \pm 14.7(4.0 \% \downarrow)$ \\
\hline
\end{tabular}

The results expressed as mean $\pm \mathrm{SD}$ and corresponding value of "Before session" percentage. $* \mathrm{p}<0.05$ compare with 
Table (2): Effects of laboratory stress on the hemodynamic parameter at standing position.

\begin{tabular}{|l||l||l||l|l||}
\hline \multicolumn{1}{|c||}{} & \multicolumn{2}{|c||}{ Female (n=14) } & \multicolumn{2}{c||}{ Male (n=7) } \\
\hline \hline & Before session & After session & Before session & After session \\
\hline \hline Heart Rate (bpm) & $96.6 \pm 9.5$ & $103.5 \pm 10.5$ & $104.3 \pm 8.2$ & $103.1 \pm 10.3$ \\
Systolic BP (mmHg) & $119.4 \pm 13.1$ & $115.4 \pm 9.7$ & $134.6 \pm 8.3$ & $133.6 \pm 13.5$ \\
Diastolic BP (mmHg) & $79.0 \pm 7.9$ & $82.6 \pm 7.9$ & $87.7 \pm 7.8$ & $89.6 \pm 5.7$ \\
Pulse pressure (mmHg) & $40.4 \pm 12.5$ & $32.8 \pm 7.2^{*}$ & $46.9 \pm 9.3$ & $44.0 \pm 12.0$ \\
Mean arterial BP (mmHg) & $92.4 \pm 8.0$ & $93.6 \pm 7.8$ & $103.3 \pm 6.7$ & $104.2 \pm 7.1$ \\
Myocardium workload & $116 \pm 21.3$ & $119.8 \pm 18.2(3.3 \% \uparrow)$ & $140.5 \pm 15.5$ & $137.0 \pm 11.9(2.5 \% \downarrow)$ \\
\hline
\end{tabular}

The results expressed as mean $\pm \mathrm{SD}$ and corresponding value of "Before session" percentage. $* \mathrm{p}<0.05$ compare with

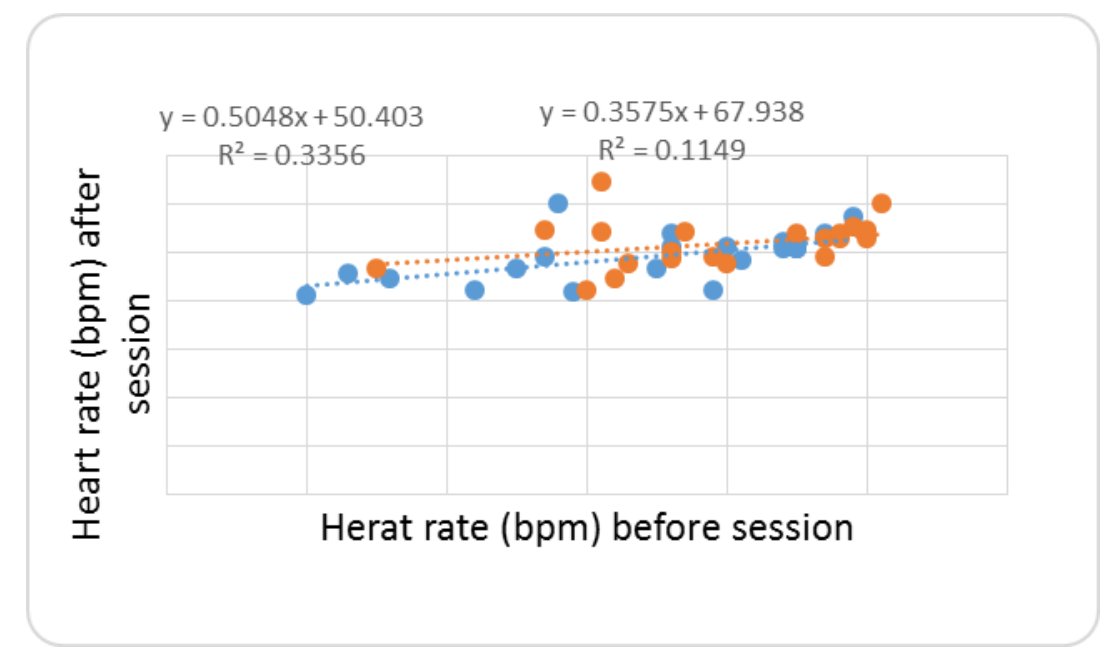

Figure (1): Correlation between heart rate before with after the session in respect to the posture.

\section{Discussion}

In the present study Table (1) show that heart rate significant in female before and after session [7] and no change in the male before or after session [8] . Also the systolic for female in the sitting position appeachange and its significant and diastolic in $(\mathrm{mmHg})$ show significant in $\mathrm{SD} \pm(9.7)$ before and after session [9], where in male with siting before session appear that systolic $(139.3 \pm 10.3)$ decrease after session by $(134.7 \pm 9.5)$ it is decrease, where diastolic increase by 
(94.4 \pm 4.9$)$ [10]. Pulse pressure in siting show increase for female before and after session [11],where for male after session decrease were $\mathrm{SD} \pm$ (10.8) significant [12]. Mean arterial show little change for female and male, in the siting position before and after session [13], myocardium work loud in female were significant in change before and after [14]. Also in male the change appear decrease by( 133.6 \pm 14.7$)$ [15]. The value in the total in the siting positions its increase by $(9.7 \%)$ in female, where decrease in male by $(4.0 \%)$.

In Table (2) the standing position of the two group female and male heart rate show increase by $(10.3 \pm 10.5)$ than before [16], no change in the male before and after. Systolic and diastolic for female show significant change in both, no change in male systolic but some change in diastolic (89.6 \pm 5.7$)$. Pulse pressure in $(\mathrm{mmHg})$ for female and male before and after session significant with standing position [17]. Mean arterial significant in both female and male before and after session. Myocardium work loud for female significant (116 \pm 21.3$)$ before $(119.8 \pm 18.2)$ after session male decrease before and after session.

A total value for female after session in the siting position increased by $(9.7 \%)$ where male decrease by $(4.0 \%)$. In the standing position a total value for female increased by (3.3\%) after session but male total value decrease by $(2.5 \%)$ [18].

Figure (1) also show a correlation in the heart rate for siting position where $\mathrm{R} 2=$
(0.3356) and for standing position $\mathrm{R} 2=$ (0.1149).

\section{Conclusions}

Find from this study that female total value increased on the siting and standing position where male decrease in both position.

\section{References}

[1]Wu S. hung Z., Yang X., Li S., Zhao H, Ruan C., Wu Y., Xin A., Li K. and Cai J., "Cardiovascular events in aprehypertensive Chinese population: four-year follow-up study". International Journal of Cardiology.167:2196-9. 2104.

[2]Karl Peltzer, Supa Pengpid, Vanphanom Sychareun, Alice Joan G. Ferrer, Wah Yun Low, Thang Nguyen Huu, Hla Hla Win, Erna Rochmawati, and Niruwan Turnbull, "Prehypertension and psychosocial risk factors among university students in ASEAN countries". 23-Aug-2017.

[3]Gopal Krushna Pal, Chandrasekaran Adithan, Jagadeeswaran Indumathy, Balasubramanian Suchitra Int J Clin Exp Physiol, "Myocardial works stress is linked to sympathovagal imbalance in prehypertensives". Volume: 2 Issue: 2. Page: 134-136. 2015.

[4]Richard Gordan, Judith K Gwathmey,and Lai-Hua Xie, "Autonomic and endocrine control of cardiovascular function". World J. Cardiol. 7(4): 204-214. 2015.

[5]Mette S. Olufsen, Johnny T. Ottesen, Hien T. Tran, Laura M. Ellwein, Lewis A. Lipsitz, and Vera Novak." Blood pressure and blood flow variation during postural change from sitting to standing: model 
development and validation". J Appl Physiol. 99(4): 1523-1537. 2005.

[6] Saba Kalantary, Ali Dehghani, Mir Saeed Yekaninejad, Leila Omidi, and Mitra Rahimzadeh, "The effects of occupational noise on blood pressure and heart rate of workers in an automotive parts industry". ARYA Atheroscler. 11(4): 215-219. Jul2015.

[7]Smith P, Ma H, Glazier RH, GilbertOuimet M, Mustard C. and Am J Epidemiol., "The Relationship Between Occupational Standing and Sitting and Incident Heart Disease". Over a 12-Year Period in Ontario, Canada. 187(1):27-33. 1-Jan-2018.

[8]David V. B. James, Steven C. Munson, Sara Maldonado-Martin, and Mark B. A., " De Ste Croix Heart Rate Variability: Effect of Exercise Intensity on Postexercise Response". The American Alliance for Health, Physical Education, Recreation and Dace. Vol. 83, No. 4, pp. 533-539. 2012.

[9]Sandro Lemos, Tiago Figueiredo, Silvio Marques, Thalita Leite, Diogo Cardozo, Jeffrey M. Willardson, and Roberto Simao,. "Effects of Strength Training Sessions Performed with Different Exercise Orders and Intervals on Blood Pressure and Heart Rate Variability". Int J Exerc Sci. 11(2): 5567. 2018 May 1. 2018.

[10] Benetos A, Zureik M, Morcet J, Thomas F, Bean K, Safar M, Ducimetière $P$ and Guize L.,"A decrease in diastolic blood pressure combined with an increase in systolic blood pressure is associated with a higher cardiovascular mortality in men". Journal of the American College of
Cardiology .Volume 35, Issue 3, Pages 673680. 2000.

[11]Arima H, Murakami Y, Lam TH, Kim HC, Ueshima H, Woo J, Suh I, Fang X, and Woodward M." Effects of prehypertension and hypertension subtype on cardiovascular disease in the Asia-Pacific Region". Hypertension; 59(6):1118-23. 2012.

[12]Mohammad Reza Shahraki, Hamideh Mirshekari, Ahmad Reza Shahraki, Elham Shahraki, and Marzieh Naroi. "Arterial blood pressure in female students before, during and after exercise": ARYA Atheroscler ; 8(1): 12-15. 2012.

[13]Nobuhiro Watanabe, John Reece, and Barbara I ." Effects of body position on autonomic regulation of cardiovascular function in young, healthy adults". Chiropr Osteopat; 15:19. 2007.

[14]Hideo A Baba and Jeremias Wohlschlaeger."Morphological and Molecular Changes of the Myocardium after Left Ventricular Mechanical Support".Curr Cardiol Rev; 4(3): 157-169. 2008

[15] Choi B1, Schnall PL, Yang H, Dobson M, Landsbergis P, Israel L, Karasek R, Baker D. "Sedentary work, low physical job demand, and obesity in US workers"; Am J Ind Med;53(11):1088-101. 2010.

[16]Zafer Buyukterzi, Ozcan Ozeke, Mehmet Fatih Ozlu, Aytun Canga, Ozgul Malcok Gurel, Tumer Erdem Guler, Veli Kaya, Firat Ozcan, Serkan Cay, Serkan Topaloglu, and Dursun Aras."Heart Rate Acceleration and Recovery Indices are Not Related to the Development of Ventricular Premature Beats During Exercise Test". 
Zhonghua Minguo Xin Zang Xue Hui Za Zhi; 30(4): 259-265. 2014.

[17]G S Bimenya, W Byarugaba, S Kalungi, J Mayito, $\mathrm{K}$ Mugabe, $\mathrm{R}$ Makabayi, $\mathrm{E}$ Ayebare, H Wanzira, and M Muhame." Blood pressure profiles among Makerere University undergraduate students". Afr Health Sci; 5(2): 99-106. 2005.

[18]Pulsford R, Stamatakis E, Britton AR, Brunner EJ, Hillsdon M. "Associations of sitting behaviours with all-cause mortality over a 16-year follow-up: the Whitehall II study". Int J Epidemiol; 44(6):1909-16. 2015. 